\title{
Loss Analysis of Vehicle-to-Grid Operation
}

\author{
Shuang Gao, K. T. Chau, C. C. Chan and Diyun Wu \\ Department of Electrical and Electronic Engineering \\ The University of Hong Kong \\ Hong Kong \\ sgao@eee.hku.hk
}

\begin{abstract}
The plug-in hybrid electric vehicle (PHEV) with vehicle-to-grid (V2G) capability is becoming increasingly popular and can be expected to deploy in a large scale. According to the estimation of PHEV penetration degree and the charging characteristics, the modeling of distribution grid with extra load of PHEV charging is formulated first. The PHEVs plugged into the grid, when aggregated in a considerable number, constitute a new load. The impacts of this extra load on the grid are analyzed by power flow simulation in terms of power losses and voltage variation. Uncontrolled charging and optimal charging scenarios are compared in the 33-bus test system. The results indicate the possible problem caused by charging PHEVs and the necessity of building a new control scheme to schedule the generation and the charging profile in the grid. Thus the optimization algorithm is designed to minimize the power losses, and enhance the power quality of the grid as well. The improved model with further constraints for practical application of $\mathrm{V} 2 \mathrm{G}$ is discussed. In this model, the ability to schedule both charging and discharging of PHEVs with V2G technology is presented.
\end{abstract}

Keywords - power loss minimization; plug-in hybrid electric vehicle; distribution grid; vehicle-to-grid operation

\section{INTRODUCTION}

Due to the increase in fossil fuel prices, growing concern for environmental pollution and the demand for renewable energy [1-9], electric vehicles (EVs) have attracted much attention in recent years. Among them, the plug-in hybrid EV (PHEV) is considered as a promising solution for electrification of transportation sector and being introduced rapidly into the market [10-14]. As offered by several major auto manufacturers, the PHEV can be charged to store the energy by connection to electricity outlet, and have the capability to supply the energy storage to grid by discharging the battery [15-19]. Different PHEV topologies were proposed to make the bi-directional power transfers possible using power electronics [20-26]. The aggregation of PHEVs plugged in the distribution grid acts as an additional load. In order to estimate the PHEV penetration degree over the next few years, the analyses of PHEV electrical consumption were carried out [27], which indicated that the penetration of PHEVs in 13 US regions would be up to $25 \%$ by 2020 and challenge the accommodation ability of the current power system so that new power plants would be required to handle this load of charging PHEVs.
The aggregation of a sizable number of the PHEVs as a significant load by battery charging may have impacts on distribution system thermal loading, voltage regulation, transformer loss of life, unbalance, losses and harmonic distortion levels [28]. Some previous EV integration studies eliminated the effects of this extra load on the peak demand by assuming the off-peak charging scenario. Such assumptions may fail to figure out the practical effects of the possible variations of PHEV load on the existing system capacity. In this paper, the impacts will be assessed in terms of power losses and voltage deviations. A MATLAB model is built to simulate the distribution grid with the PHEV penetration. The results manifest the challenge of grid operation even though the PHEVs are charged in the off-peak time. It will cause a high risk of overload when the battery charging occurs near the daily peak; therefore, proper rescheduling of the grid operation is indispensable for the PHEVs integrated to the grid. An optimal control method for PHEV charging management is proposed to minimize the power losses. From the simulation results, the ability of PHEV discharging into the grid can replace conventional capacity that provides peaking capacity, thus enhance the power quality.

\section{IMPACT OF CHARGING PHEVS}

The aggregation of PHEVs conducts as additional electricity demand in the power system. The basic principle for optimal PHEV charging is to settle this additional load during night or the off-peak period. The results indicate that scheduling PHEV charging load is essential to prevent overloading system elements and voltage magnitudes that are intolerable.

\section{A. PHEV charging problem formulation}

To simulate charging of PHEVs in the distribution grid, A model is adopted to simulate the additional load from PHEVs plus the base load in power system operation on an hourly basis for an entire day [29]. In this study, the incremental load demand with PHEV charging on each node is identified, along with its effect on the line loss and voltage drop.

The first vehicle charging scenario considered in this study is the uncontrolled charging. An overall penetration of 800 PHEVs is assumed, less than $10 \%$ of total electricity consumption in the distribution system. The PHEVs are mainly charged at public charging stations and the charging 
points for vehicle owners who live in apartment complexes or higher density urban dwellings where the parking lots have recharging infrastructure installed. That is, PHEV loads are more likely to be clustered in certain sites increasing the production for negative distribution system impacts. Thus, the PHEV load demand assembles at several nodes in a 33-bus standard distribution system [30] as shown in Fig. 1. The middle point of the charging period is chosen to show the power flow results in single-time spot figures. In this case, vehicle owners charge their vehicles at home when they come back from the work place [31]. The PHEV begins charging as soon as it is plugged in the grid at a constant power input until the battery is fully charged. The battery pack holds $9 \mathrm{kWh}$ of energy and there is a $90 \%$ efficiency for the on-board/off-board charger [32-34]. For exemplification, all PHEVs are plugged into a $220 \mathrm{~V} / 13 \mathrm{~A}$, the power rating of Hong Kong residential electricity outlet, operating at a maximum charging rate of $2.8 \mathrm{~kW}$. Although this is the low charging mode for common household circuit, the PHEV can be fully charged within 4 hours.
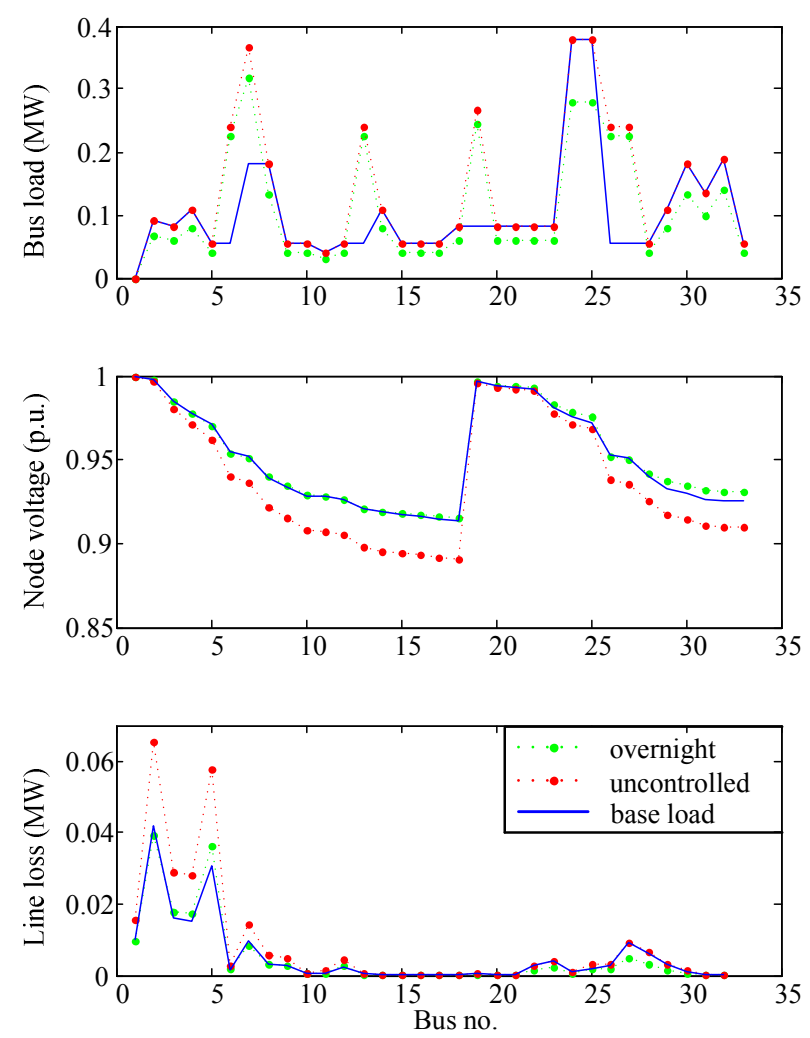

Figure 1. Node voltages and line losses of daytime charging in 33-bus grid

Fig. 2 illustrates the daily electricity demand pattern in Hong Kong with PHEV charging. The daily uncontrolled charging profile ramps up rapidly from $7 \mathrm{pm}$ to $9 \mathrm{pm}$ at the end of the normal workday and reaches the most charging capacity in the mid or late evening. The number of the PHEVs charged at certain time is varied by a normal distribution function. The standard deviation $\sigma$ is determined in such a way that all the PHEVs are fully charged by the end of the charging period, namely 3:00 am. For evaluating the impact of PHEV charging on a daily basis, the hourly voltage profile of the node with a lower average voltage magnitude and the total power loss is illustrated in Fig. 2.

\section{B. Analysis of power flow results}

The uncontrolled charging cases add considerable load coincident with periods of high demand, and add to the peak capacity requirements. New electricity generation capacity is required for this additional PHEV load to reduce the power loss and enhance the power quality of the distribution network.

In order to reduce the negative effect of PHEV load, all charging should occur in the overnight hours. This is the main point of off-peak charging scenario, aiming at matching the PHEV charging load to periods of minimum demand. This allows the use of most optimal charging electricity and improving overall system performance. The PHEV charging is dispatched in the period of minimum overnight demand starting from $11 \mathrm{pm}$ and must be completed by $7 \mathrm{am}$. The simulation results in Fig. 1 and Fig. 2 can be compared with the same items in uncontrolled charging scenarios. It shows a lower power loss and voltage drop in off-peak charging case, representing a likely optimal charging scenario.
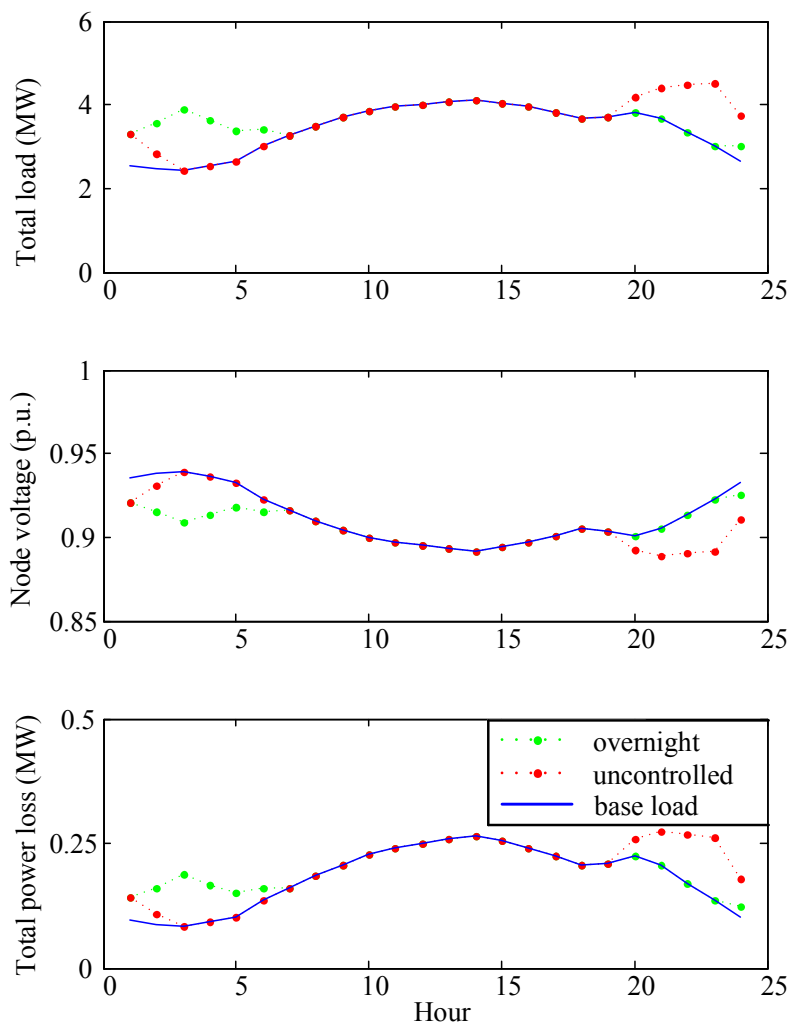

Figure 2. Hourly voltage profile and total power loss with PHEV charging

\section{OPTIMIZATION OF VEHICLE-TO-GRID OPERATION}

The integration of PHEVs into the grid has an adverse effect on the power losses and node voltage. The optimal control method is aimed to handle this battery charging load without the installation of additional generation capacity. 
Based on the concept of off-peak charging, an optimal charging algorithm is proposed and implemented.

A. Optimal algorithm for minimizing power losses

The objective of the coordinated charging scheme is to minimize power losses [29]. Interior point method [35] is used to calculate the optimal active power for charging the PHEVs in the constrained parking lots. Therefore, the objective function for power loss optimization is given by:

$$
\min P_{l o s s}=\min \sum_{t=1}^{t_{\max }} \sum_{l=1}^{l_{\max }} R_{l} I_{l}^{2}(t)
$$

This function is subject to the constraints as follows:

1. System power balance. Power supplied from the generators must satisfy the load demand, the power of charging for PHEVs and the system losses as expressed by:

$$
\sum_{i=1}^{N_{G}} P_{G i}(t)=P_{\text {load }}(t)+\sum_{i=1}^{N_{V}} P_{V i}(t)+P_{\text {loss }}(t)
$$

where $N_{G}$ is the total number of the generation resources in the system including the small-size distribution generators and limited capacity of discharging PHEVs, and $N_{V}$ is the number of PHEV charging aggregations at time $t$.

2. Generation limits. Each generation resource in a certain bus has a generation range, which is defined as:

$$
P_{i}^{\min } \leq P_{G i}(t) \leq P_{i}^{\max }
$$

3. Ramp rate. The output of individual generation resource and $\mathrm{V} 2 \mathrm{G}$ power rate is limited by ramp-up and ramp-down rates at each hour, which is represented as:

$$
\begin{aligned}
& \max \left(P_{i}(t-1)-R D_{i}, P_{i}^{\mathrm{min}}\right) \leq P_{i}(t) \\
& \leq \min \left(P_{i}(t-1)+R U_{i}, P_{i}^{\mathrm{max}}\right)
\end{aligned}
$$

Where $R U_{i}$ and $R D_{i}$ are the ramp-up and ramp-down rates of generation resource $i$.

4. The initial SOC of PHEV load. The state of charge (SOC) of the batteries [36-38] at the beginning of the charging period must be considered in the optimal algorithm as each PHEV parked in the recharging place has some energy stored in the battery:

$$
C_{o i}=\sum_{n i=1}^{n i=n_{V i}} C_{i, s o c}=n_{V i} C_{i, a v g}
$$

where $C_{o i}$ is the initial battery energy of PHEV aggregation, $n_{V i}$ is the number of PHEVs aggregated at each node, $C_{i, s o c}$ is the initial SOC of each PHEV, and $C_{i, a v g}$ is the mean value of the PHEV initial SOC predetermined in accordance with the characteristic of vehicle on-board battery pack.

5. Total energy for PHEV charging. It is expressed as:

$$
\sum_{t=1}^{t_{\max }} P_{V i}(t) T=C_{i, \max }-C_{o i}
$$

where $T$ is the time interval and $C_{i, \max }$ is the amount of electrical energy required to recharge the vehicle on account of the battery capacity and charger efficiency.

6. The limit of PHEV charging rate. The PHEV battery charging power regulated by the on-board/off-board charger should be restricted in a reasonable range:

$$
P_{V i}^{\min } \leq P_{V i} \leq P_{V i}^{\max }
$$

where $P_{V i}{ }^{m i n}$ is the minimal recharging rate, and the $P_{V i}{ }^{\max }$ is the continuous power rating on the name plate of electricity outlet.

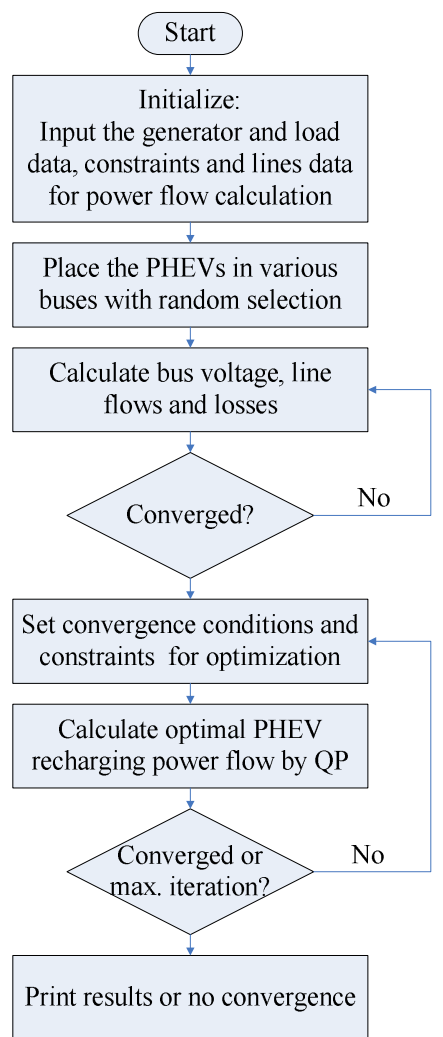

Figure 3. Flowchart of optimal PHEV charging.
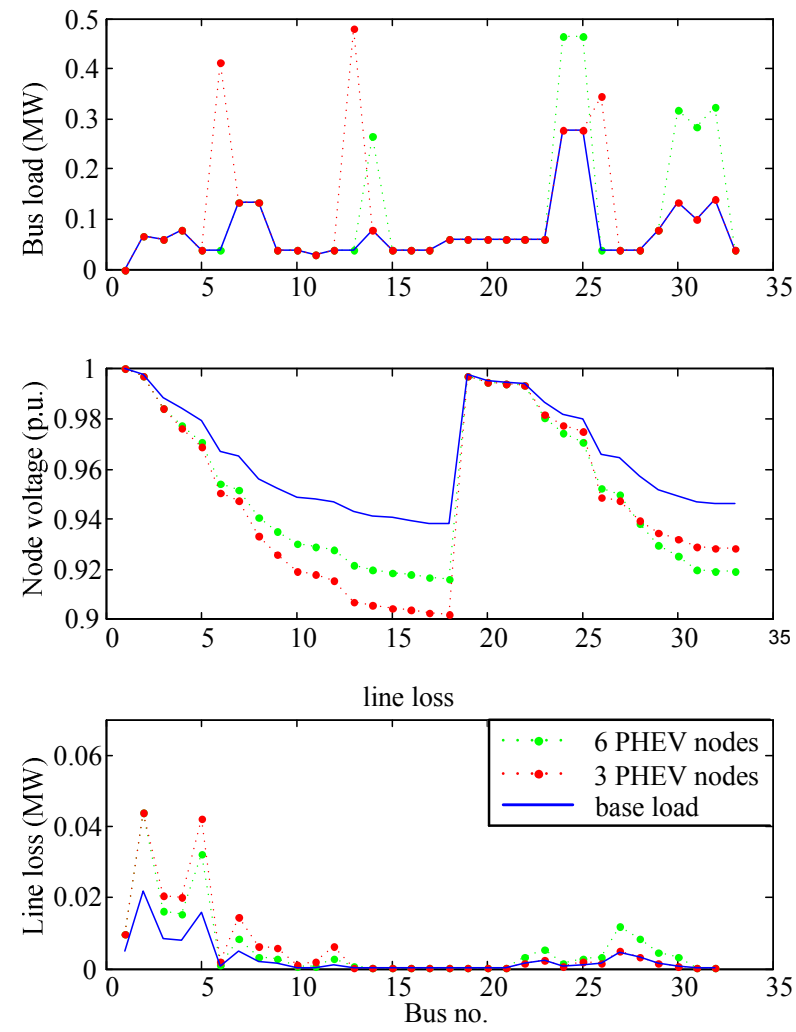

Figure 4. Node voltages and line losses in off-peak charging 
The flowchart of the proposed method is shown in Fig. 3. The power flow analysis is implemented first using the input data of the 33-bus system with PHEV charging load. The results of the initial iterative calculation are used for the optimal scheduling of the generation resources and load demands. While the potential use for PHEVs is as distributed electrical sources, the first case only considers the loading characteristics. The primary feeder is the sole electrical resource in the 33-bus distribution network. In reality, specific areas have a higher concentration of PHEVs. So in this case, all the PHEVs are assumed to be distributed at the three nodes chosen randomly, but the numbers of the PHEV aggregation at each node are not evenly through the nodes. The ratio of the PHEV charging demand at the three nodes is presumed to be 11:13:9, which can be observed in Fig. 4 and compared to the previous PHEV distribution scheme.

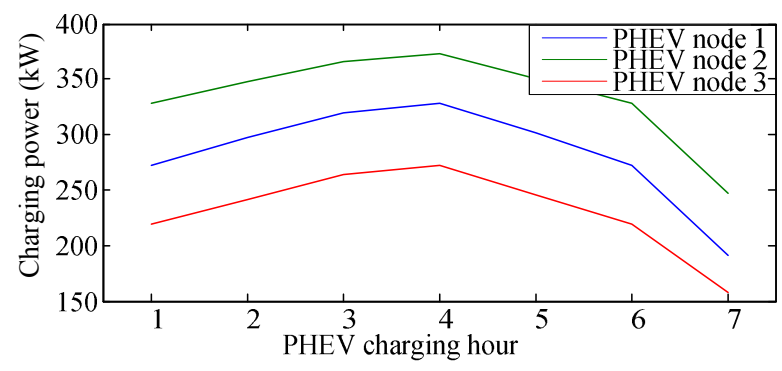

Figure 5. PHEV charging profiles with optimal charging

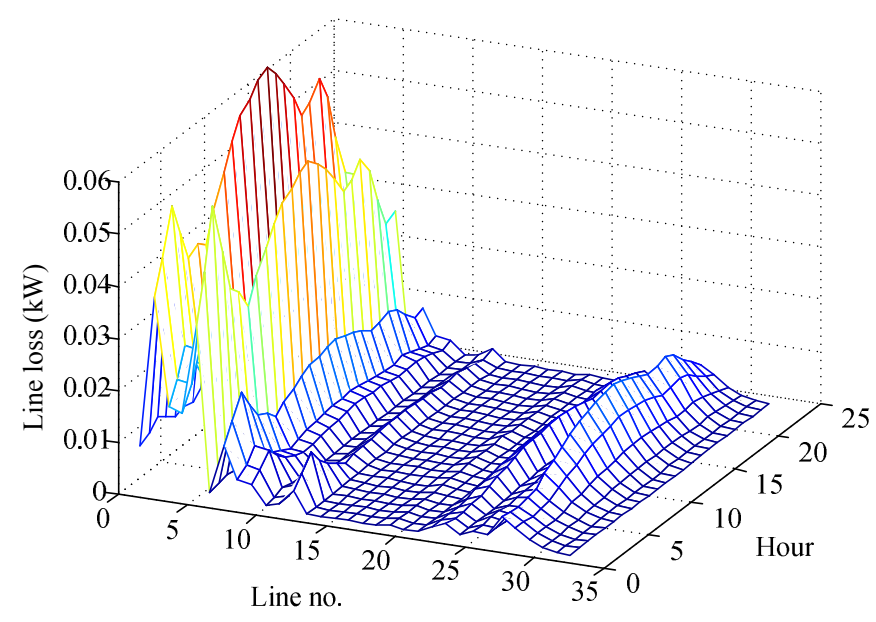

Figure 6. Line losses with optimal charging

The optimal load management is deployed to coordinate the charging of PHEVs at different nodes in manner to minimize the total power loss. The PHEV charging power at each node is depicted in Fig. 5 based on the solution of optimal algorithm. Fig. 6 shows the results of load flow analysis in terms of node voltage magnitude and transmission line loss during the PHEV charging period and the entire day respectively. In the previous section, the power of battery charger is fixed and kept constant until fully charged. For the optimal PHEV charging, the battery charging rate of individual PHEV needs to be coordinated with respect to the solutions of optimal algorithm. It is variable such that the aggregation of the PHEV charging becomes the controllable load.
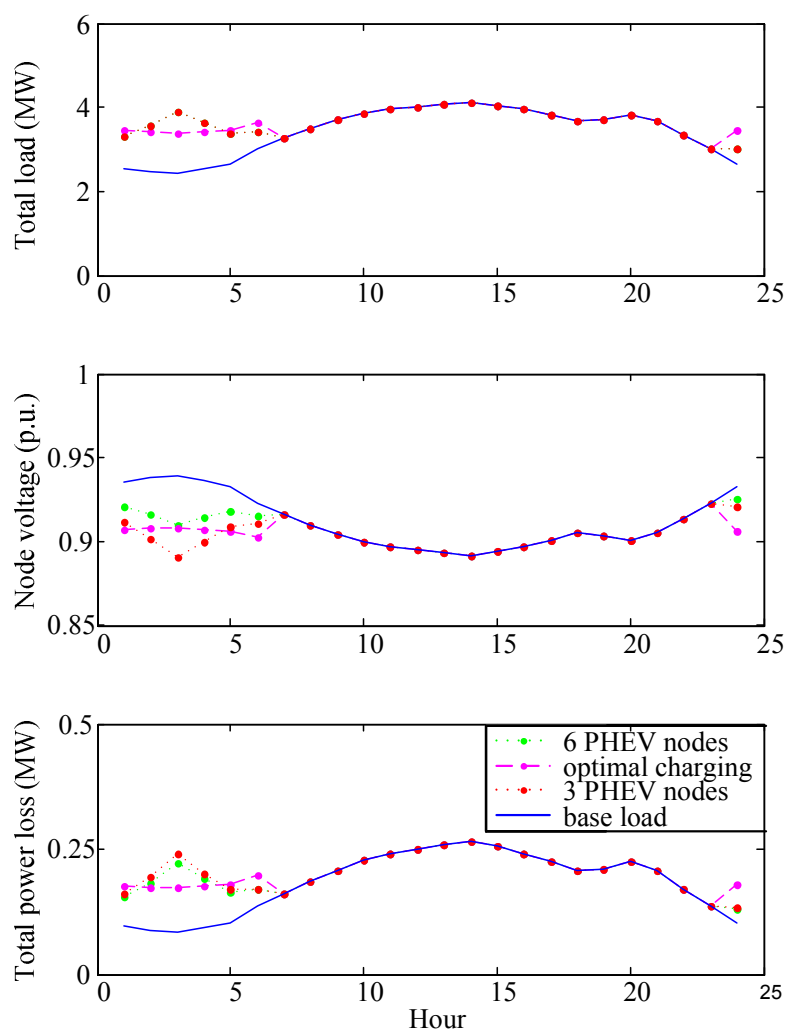

Figure 7. Hourly voltage profile and total power loss in off-peak charging.

Fig. 7 shows the comparison of optimal charging with the delayed charging scenarios, in which the blue line represents the normal load condition, the red and green dotted lines represent delayed charging scenarios when the total PHEV load is distributed at three nodes and six nodes with random selection respectively, and the purple dotted line is for the optimal charging scenario. It can be found that the proposed optimal charging scheme can reduce the voltage deviation below $10 \%$ of the distribution nominal voltage and minimize the power loss as well. The optimal charging strategy is coordinated to match the off-peak electrical demand by timing and diversifying the PHEV load, and thereby mitigate the impact of the additional PHEV load on the distribution network.

\section{B. Improved algorithmic model for $V 2 G$ operation}

In the previous section, only the PHEV charging load is added with the assumption that no PHEV resource is available in the grid. More sophisticated conditions need to be applied in the optimal algorithm with V2G capacity. The aggregation of PHEVs with V2G capability can act as a controllable load or a generation resource. The value of the SOC of battery is adopted to determine the selection of PHEVs in the aggregation of generation or load. The SOC of $80 \%$ is stipulated as the measure preliminarily in this work, that is, 
the PHEV is chosen for discharging when its SOC reaches $80 \%$ or above.
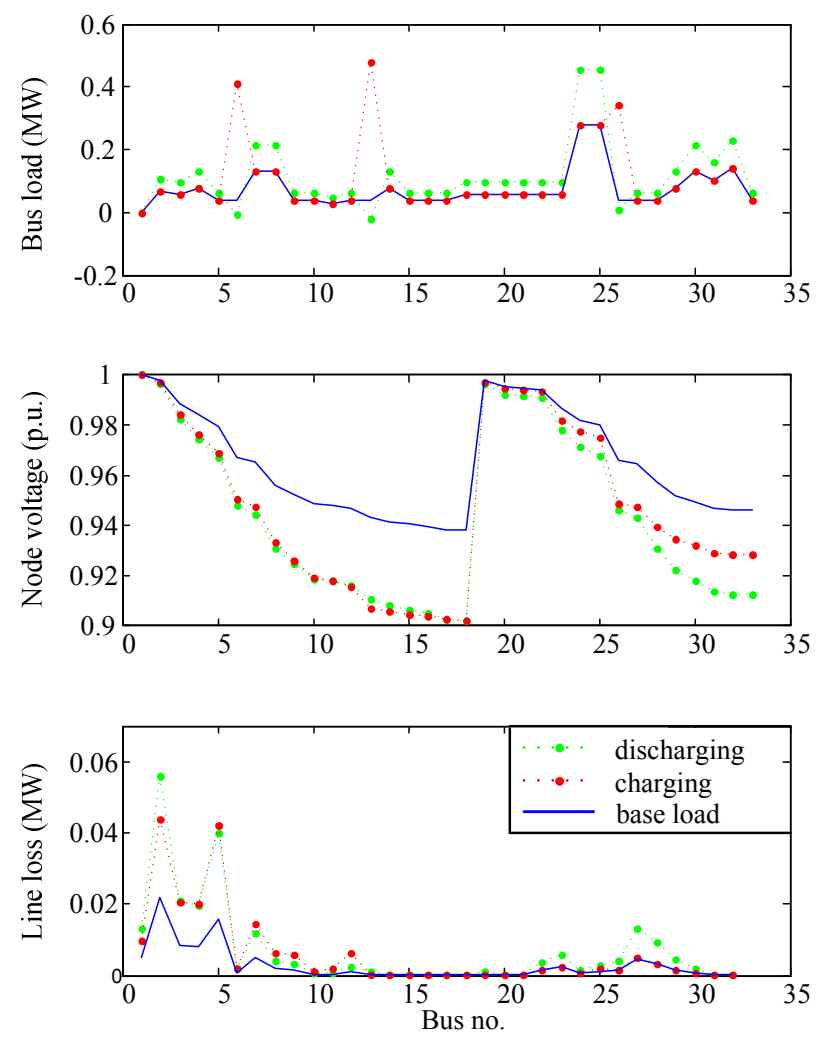

Figure 8. Node voltages and line losses with PHEV discharging
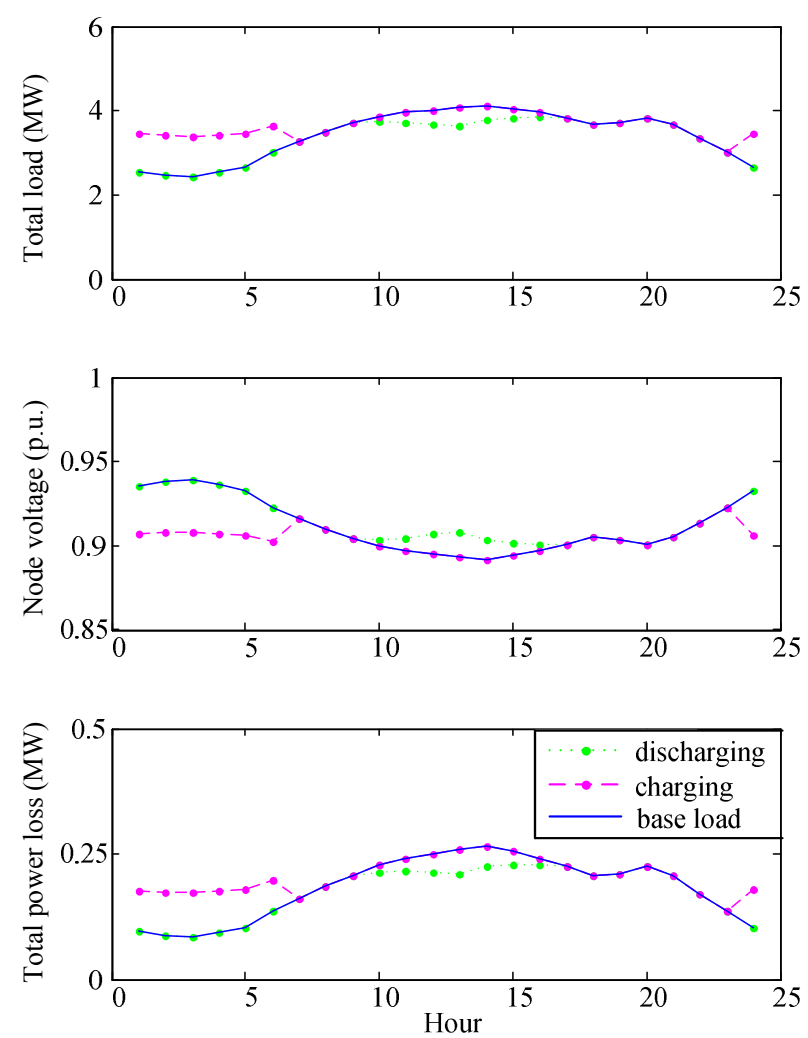

Figure 9. Hourly voltage profile and power loss with PHEV discharging
Furthermore, the ability of PHEV discharging into grid can also be evaluated by using this simulation model and algorithm. It should be noted that even a small size of PHEV discharging aggregation can provide peaking and peak reserve capacity, especially during the peak demands. In the 33-bus system simulation with V2G capability, only less than $20 \%$ of PHEV charging amount in previous scenarios is added to provide discharge capacity while the PHEV fleets are placed in the same nodes as in the PHEV charging simulation. The algorithm can also be adopted to schedule a very limited PHEV discharging capacity that can significantly improve the performance of distribution grid. A PHEV discharging coordination segment is added in the above optimal algorithm.

When the maximum voltage drop is above $10 \%$ of the nominal voltage magnitude, power is supplied to the grid from the vehicle's battery. Although the available discharging energy is small, the results in Fig. 8 and Fig. 9 show a substantial reduction of power loss and the improvement of voltage stability. The $\mathrm{V} 2 \mathrm{G}$ energy is supplied to make sure the voltage drop is within $10 \%$, which can meet the voltage standard defined in EN50160 [39], and improve the grid-buffering capability of the PHEV aggregation.

\section{CONCLUSION}

The implementation of the proposed optimal algorithm is based on the framework of distribution grid with the integration of PHEVs. The role of aggregator is to group together a sizable number of PHEVs to be a useful load or generation device. A computer-communication network must be established to accomplish two-way data transfer between the vehicle side and the energy service provider (ESP). In this paper, the impacts of PHEV charging on distribution systems are evaluated by performing power flow analysis. The optimal algorithm is designed to minimize the power loss and enhance the efficient operation of the distribution network. The V2G capacity of PHEVs that can be modeled as a controllable load or generation resource in the distribution system is put into the optimal algorithm. The extra PHEV loads distributed at different nodes are diversified by adjusting the charging power so as to offset the need for additional generating capacity. The PHEV discharging energy management is added in the optimal algorithm, where V2G services are offered when the voltage drop exceeds the distribution voltage deviation standard defined in EN50160. The simulation model is developed for the interaction between PHEVs and the power grid, and the results show the potential benefits of optimal V2G operation.

\section{ACKNOWLEDGMENT}

This work was supported by a grant (Project code: 200907176028) from the Committee on Research and Conference Grants, The University of Hong Kong, Hong Kong Special Administrative Region, China.

\section{REFERENCES}


[1] Y. Fan, K.T. Chau and M. Cheng, "A new three-phase doubly salient permanent magnet machine for wind power generation," IEEE Transactions on Industry Applications, vol. 42, no. 1, January/February 2006, pp. 53-60.

[2] Y. Fan, K.T. Chau and S. Niu, "Development of a new brushless doubly fed doubly salient machine for wind power generation, IEEE Transactions on Magnetics, vol. 42, no. 10, October 2006, pp. 3455-3457.

[3] K.T. Chau, Y.B. Li, J.Z. Jiang and S. Niu, "Design and control of a PM brushless hybrid generator for wind power application," IEEE Transactions on Magnetics, vol. 42, no. 10, October 2006, pp. 3497-3499.

[4] S. Niu, K.T. Chau, J.Z. Jiang and C. Liu, "Design and control of a new double-stator cup-rotor permanent-magnet machine for wind power generation," IEEE Transactions on Magnetics, vol. 43, no. 6, June 2007, pp. 2501-2503.

[5] M.S.W. Chan and K.T. Chau, "A switched-capacitor boost-multilevel inverter using partial charging," IEEE Transactions on Circuits and Systems II, vol. 54, no. 12, December 2007, pp. 1145-1149.

[6] C. Yu, K.T. Chau and J. Z. Jiang, "A flux-mnemonic permanent magnet brushless machine for wind power generation," Journal of Applied Physics, vol. 105, no. 7, April 2009, paper no. 07F114, pp. 1-3.

[7] L. Jian, K.T. Chau and J.Z. Jiang, "A magnetic-geared outer-rotor permanent-magnet brushless machine for wind power generation," IEEE Transactions on Industry Applications, vol. 45, no. 3, May/June 2009, pp. 954-962.

[8] C. Yu and K.T. Chau, "Thermoelectric automotive waste heat energy recovery using maximum power point tracking," Energy Conversion and Management, Vol. 50, No. 6, June 2009, pp. 1506-1512.

[9] C. Liu, K.T. Chau and X. Zhang, "An efficient wind-photovoltaic hybrid generation system using doubly-excited permanent-magnet brushless machine," IEEE Transactions on Industrial Electronics, vol. 57, no. 3, March 2010, pp. 831-839.

[10] C.C.Chan and K.T.Chau, Modern Electric Vehicle Technology. Oxford University Press, 2001.

[11] K.T. Chau and C.C. Chan, "Electric vehicle technology - a timely course for electrical engineering students," International Journal of Electrical Engineering Education, vol. 35, no. 3, July 1998, pp. 212-220.

[12] K.T. Chau, Y.S. Wong and C.C. Chan, "EVSIM - a PC-based simulation tool for electric vehicle technology course," International Journal of Electrical Engineering Education, vol. 37, no. 2, April 2000, pp. 167-179.

[13] K.T. Chau and C.C. Chan, "Emerging energy-efficient technologies for hybrid electric vehicles," Proceedings of IEEE, vol. 95, no. 4, April 2007, pp. 821-835.

[14] K.T. Chau, C.C. Chan and C. Liu, "Overview of permanent-magnet brushless drives for electric and hybrid electric vehicles," IEEE Transactions on Industrial Electronics, vol. 55, no. 6, June 2008, pp. 2246-2257.

[15] M. Anderman, "The challenge to fulfill electrical power requirements of advanced vehicles," Journal of Power Sources, vol. 127, no. 1, pp. 2-7, Nov. 2004.

[16] A. Ipakchi and F Albuyeh, "Grid of the future," IEEE Power and Energy Magazine, vol. 7, no. 2, pp. 52-62, Jan. 2010.

[17] K.T. Chau, Y.S. Wong and C.C. Chan, "An overview of energy sources for electric vehicles," Energy Conversion and Management, vol. 40, no. 10, July 1999, pp. 1021-1039.

[18] K.T. Chau and Y.S. Wong, "Hybridization of energy sources in electric vehicles," Energy Conversion and Management, vol. 42, no. 9, June 2001, pp. 1059-1069.

[19] K.T. Chau and Y.S. Wong, "Overview of power management in hybrid electric vehicles," Energy Conversion and Management, vol. 43, no. 15, June 2002, pp. 1953-1968.

[20] C.C. Chan and K.T. Chau, "An overview of power electronics in electric vehicles," IEEE Transactions on Industrial Electronics, vol. 44, no. 1 , February 1997 , pp. 3-13.
[21] K.T. Chau, J.M. Yao and C.C. Chan, "A new soft-switching vector control approach for resonant snubber inverters," International Journal of Electronics, vol. 86, no. 1, January 1999, pp. 101-115.

[22] K.T. Chau, T.W. Ching and C.C. Chan, "A new two-quadrant zero-voltage transition converter for DC motor drives," International Journal of Electronics, vol. 86, no. 2, February 1999, pp. 217-231.

[23] T.W. Ching and K.T. Chau, "A new two-quadrant zero-current transition converter for DC motor drives," International Journal of Electronics, vol. 88, no. 6, June 2001, pp. 719-735.

[24] S.Z. Jiang, K.T. Chau and C.C. Chan, "Harmonic reduction in dc-link current of a dual-inverter pole-changing induction motor drive for electric vehicles," Electric Power Components and Systems, vol. 31, no. 11, November 2003, pp. 1063-1081.

[25] M.S.W. Chan and K.T. Chau, "A switched-capacitor boost-multilevel inverter using partial charging," IEEE Transactions on Circuits and Systems II, vol. 54, no. 12, December 2007, pp. 1145-1149.

[26] M.M. Morcos, N.G. Dillman and C.R. Mersman, "Battery chargers for electric vehicles," IEEE, Power Engineering Review, vol. 20, no. 11, pp. 8-11, Dec. 2000.

[27] C. Guille and G. Gross, "A conceptual frame work for the vehicle-to-grid (V2G) implementation," Energy Policy, vol. 37, no. 11, pp. 4379-4390, Nov. 2009.

[28] P. Evans, S. Kuloor and B. Kroposki, Impacts of Plug-in Vehicles and Distributed Storage on Electric Power Delivery Networks. National Renewable Energy Laboratory, 2009.

[29] K. Clement, E. Haesen and J Driesen, "Stochastic analysis of the impact of plug-in hybrid electric vehicles on the distribution grid," International Conference and Exhibition on Electricity Distribution, 2009, pp. 1-4.

[30] Naresh Acharya, Pukar Mahat, N.Mithulanathan, "An analytical approach for DG allocation in primary distribution network", Electric Power and Energy Systems, vol. 28, pp. 669-678, 2006.

[31] A.Y. Saber and G.K. Venayagamoorthy, "Intelligent unit commitment with vehicle-to-grid - A cost-emission optimization," Journal of Power Sources, vol. 195, no. 3, pp. 898-911, Mar. 2010.

[32] W.X. Shen, C.C. Chan, E.W.C. Lo and K.T. Chau, "Adaptive neuro-fuzzy modeling of battery residual capacity for electric vehicles," IEEE Transactions on Industrial Electronics, vol. 49, no. 3, June 2002, pp. 677-684.

[33] W.X. Shen, C.C. Chan, E.W.C. Lo and K.T. Chau, "A new battery available capacity indicator for electric vehicles using neural network," Energy Conversion and Management, vol. 43, no. 6, April 2002, pp. 817-826.

[34] W.X. Shen, C.C. Chan, E.W.C. Lo and K.T. Chau, "Estimation of battery available capacity under variable discharge currents," Journal of Power Sources, vol. 103, no. 2, January 2002, pp. 180-187.

[35] R.H. Byrd, J.C. Gilbert, and J. Nocedal, "A trust region method based on interior point techniques for nonlinear programming," Mathematical Programming, vol 89, no. 1, pp. 149-185, 2000.

[36] K.T. Chau, K.C. Wu, C.C. Chan and W.X. Shen, "A new battery capacity indicator for nickel-metal hydride battery powered electric vehicles using adaptive neuro-fuzzy inference system," Energy Conversion and Management, vol. 44, no. 13, August 2003, pp. 2059-2071.

[37] K.T. Chau, K.C. Wu and C.C. Chan, "A new battery capacity indicator for lithium-ion battery powered electric vehicles using adaptive neuro-fuzzy inference system," Energy Conversion and Management, vol. 45, no. 11-12, July 2004, pp. 1681-1692.

[38] W.X. Shen, K.T. Chau, C.C. Chan and E.W.C. Lo, "Neural network based residual capacity indicator for nickel-metal hydride batteries in electric vehicles," IEEE Transactions on Vehicular Technology, vol. 54, no. 5, September 2005, pp. 1705-1712.

[39] CENELEC European Committee for Electrotechical Standardisation, Voltage Characteristics of Electricity Supplied by Public Distribution Systems. Std. EN50160, 1994. 